\title{
Rapid measurement of creatine kinase activity in a coronary care unit using a portable benchtop reflectance photometer
}

\author{
I GIBB, J R BARTON, P C ADAMS, D PRATT, C R DEAN, I F TARBIT
}

\begin{abstract}
Rapid measurements of plasma creatine kinase activity using an inexpensive benchtop reflectance photometer (Ames Seralyzer) and disposable reagent strips were evaluated in the laboratory and coronary care unit. The system proved simple to use and capable of yielding rapid (four minutes per analysis), precise (coefficient of variation $<9 \%$ ), and accurate results (correlation with routine method 0.995 ) when used by medical staff. Creatine kinase values were available 6.5-102 hours earlier than routine laboratory data, depending on the time and day of sampling, thereby facilitating appropriate and economic patient management.

This instrument might be used to supplement the routine enzyme service for selected admissions, resulting in greatly improved availability of results and hence contributing to the early discharge of patients from intensive care facilities.
\end{abstract}

\section{Introduction}

With the development of solid phase chemical techniques and small microprocessor controlled instruments ${ }^{12}$ we can now perform many biochemical measurements at or near the patient's bedside, and this has created a growing potential for decentralised testing. ${ }^{3-5}$ This is particularly relevant in acute care medicine, where the immediate availability of results may be important in diagnosis and treatment. A major concern in such testing,

\footnotetext{
Departments of Clinical Biochemistry and Cardiology, Freeman w.i.ital, Newcastle upon Tyne NE7 7DN

I GIBB, MSC, MCB, senior biochemist

J R BARTON, MB, MRCP, registrar

P C ADAMS, BA, MRCP, senior registrar

D PRATT, BSC, biochemist

C R DEAN, $M B, C H B$, senior house officer

I F TARBIT, MSC, MCB, top grade biochemist

Correspondence to: $\mathrm{Mr}$ I Gibb.
}

however, is whether the necessary standards of accuracy and precision can be achieved, particularly by non-laboratory staff. ${ }^{6}$

We report a preliminary evaluation of determinations of creatine kinase activity performed in a coronary care unit using a small benchtop reflectance photometer, the Ames Seralyzer (Ames Division, Miles Laboratories, United Kingdom). Our aims were to investigate the performance of this instrument in the hands of both experienced laboratory personnel and medical staff who had been given basic instruction in its use.

\section{Methods}

The principles of operation of the Seralyzer have been described. ${ }^{1}$ The analytical procedure entails dilution of plasma and application to the reagent area of a bar coded disposable plastic test strip. Enzyme activity is monitored by the changing reflectance properties of the strip and it is digitally displayed within four minutes. An activity exceeding $1000 \mathrm{U} / 1$ is indicated by a flashing display and a further dilution may be analysed if desired, though for clinical interpretation this was considered unnecessary. Instrument malfunction is detected by the internal microprocessor, and coded error messages are displayed when appropriate. Calibration of the instrument was performed as necessary by laboratory personnel using calibrants supplied by the manufacturer.

Analytical performance was assessed in the laboratory over six weeks using lyophilised commercial quality control materials (Gibcotrol, Gibco New Zealand Ltd) and by comparison with creatine kinase results from the routine laboratory automated analysis using an $N$ acetyl cysteine activated coupled enzyme assay (Boehringer Corporation Ltd, United Kingdom) at $37^{\circ} \mathrm{C}$ in a Cobas-Bio centrifugal analyser (Roche Diagnostics, United Kingdom).

The clinical evaluation was undertaken over a further six weeks with the Seralyzer situated in the 10 bedded coronary care unit, all measurements being made by the medical staff on samples drawn from most routine admissions. Heparinised plasma samples were analysed according to the manufacturer's instructions. The residual plasma samples were sent to the laboratory for routine cardiac enzyme profile and the results returned to the coronary care unit through the laboratory's normal reporting system. Additional samples were provided daily from the laboratory, including a control sample of known creatine kinase activity and other samples to maintain an independent monitor of performance. 


\section{Results}

\section{LABORATORY}

Consecutive replicate analyses using the same batch of test strips and fresh pooled plasma samples with mean creatine kinase activities in the range 179-1342 U/1 gave coefficients of variation not exceeding $2 \cdot 8 \%$. The same pooled plasma samples stored at $-20^{\circ} \mathrm{C}$ were analysed over 20 days using several different batches of reagent strips. The maximum overall observed change in activity was $-5 \cdot 4^{\circ}{ }_{1}$, which is consistent with losses expected under such storage conditions.

Analyses of fresh control sera over 20 days gave values for mean activities and precision which were not significantly different for the Seralyzer and routine methods of analysis (paired Student's $t$ test, Fisher's test; $p<0.05$ ) (table I). During the period of laboratory assessment 100 plasma samples with activities up to $1400 \mathrm{U} / 1$ were analysed. The overall relation was $\mathrm{Y}$ (Seralyzer) $=1.21 \mathrm{X}$ (routine) $6.5(r=0.997)$, and this relation was used to modify the laboratory reference ranges for creatine kinase for clinical interpretation of Seralyzer values during the rest of the study (men: up to $210 \mathrm{U} / \mathrm{l}$; women: up to $175 \mathrm{U} / \mathrm{l}$ ). Although recalibration of the Seralyzer is recommended by the manufacturer on a weekly basis, no appreciable deterioration in results was observed over at least 12 days as judged by the performance of control samples.

\section{CORONARY CARE UNIT}

Table I shows the day to day performance for quality control samples analysed by medical staff. Mean values with the Seralyzer did not differ significantly from those produced by the routine method. Precision for these samples at levels 1 and 3 was also no different from that of the laboratory. Nevertheless, Fisher testing of the results on level 2 samples, which were used as the control throughout, showed precision which was poorer than for the routine laboratory method but not significantly different from the results obtained with the Seralyzer by laboratory staff.

During the evaluation 71 Seralyzer measurements of creatine kinase activity were made in patients admitted to the coronary care unit. The figure correlates these results with the creatine kinase values from the routine cardiac enzyme profile. The two results marked as open circles were due to incorrectly performed Seralyzer measurements; reanalysis showed the true results to be consistent with the observed overall correlation. Seven samples gave results greater than $1000 \mathrm{U} / 1$ but these were not further diluted and are not plotted. For 51 of the measurements the doctor decided before analysis that the result was likely to be of use in management. In 22 of these $(43 \%)$ immediate patient management was altered (table II). In only one of the 20 analyses thought less likely to be helpful was a change in management made, the patient being transferred to the ward on the basis of a normal creatine kinase activity.

TABLE I-Day to day reproducibility of Seralyzer creatine kinase results obtained in laboratory and coronary care unit compared with routine method

\begin{tabular}{|c|c|c|c|c|c|}
\hline & & & \multicolumn{3}{|c|}{ Quality control sera } \\
\hline & & & $\begin{array}{c}\text { Level } \\
1\end{array}$ & $\begin{array}{l}\text { Level } \\
2\end{array}$ & $\begin{array}{c}\text { Level } \\
3\end{array}$ \\
\hline \multirow{2}{*}{ Seralyzer } & Laboratory & $\left\{\begin{array}{l}\text { Mean }(\mathrm{U} / 1) \\
\text { Cosfficient of variation }\left("{ }^{\prime}\right) \\
\text { No }\end{array}\right.$ & $\begin{array}{l}78 \\
8 \cdot 5 \\
20\end{array}$ & $\begin{array}{c}321 \\
6 \cdot 1 \\
20\end{array}$ & $\begin{array}{c}366 \\
5 \cdot 9 \\
20\end{array}$ \\
\hline & Coronary care unit & $\left\{\begin{array}{l}\text { Mean }(U 1) \\
\text { Coefficient of variation }\left({ }^{\circ} \ldots\right) \\
\text { No }\end{array}\right.$ & $\begin{array}{l}79 \\
8 \cdot 3 \\
18\end{array}$ & $\begin{array}{c}325 \\
9 \cdot 4 \\
70\end{array}$ & $\begin{array}{c}368 \\
4 \cdot 5 \\
23\end{array}$ \\
\hline Routine & $\begin{array}{l}\text { Mean (U 1) } \\
\text { Coefficient of variat } \\
\text { No }\end{array}$ & $\operatorname{tion}\left({ }^{\prime \prime}\right)$ & $\begin{array}{l}74 \\
4 \cdot 3 \\
20\end{array}$ & $\begin{array}{l}306 \\
3 \cdot 0 \\
20\end{array}$ & $\begin{array}{c}358 \\
3 \cdot 7 \\
20\end{array}$ \\
\hline
\end{tabular}

TABLE II-Changes in management as a result of using Seralyzer in coronary care unit

\begin{tabular}{|c|c|c|c|}
\hline Action & No & Action & No \\
\hline $\begin{array}{l}\text { Transfer to ward } \\
\text { Discharge home }\end{array}$ & $\begin{array}{r}11 \\
3\end{array}$ & $\begin{array}{l}\text { Intra-aortic balloon pumping } \\
\text { Pulmonary angiography }\end{array}$ & 1 \\
\hline Further treatment $\left\{\begin{array}{l}\text { Antianginal } \\
\text { Streptokinase }\end{array}\right.$ & $\begin{array}{l}4 \\
1\end{array}$ & Echocardiography & $i$ \\
\hline Total & & & 22 \\
\hline
\end{tabular}

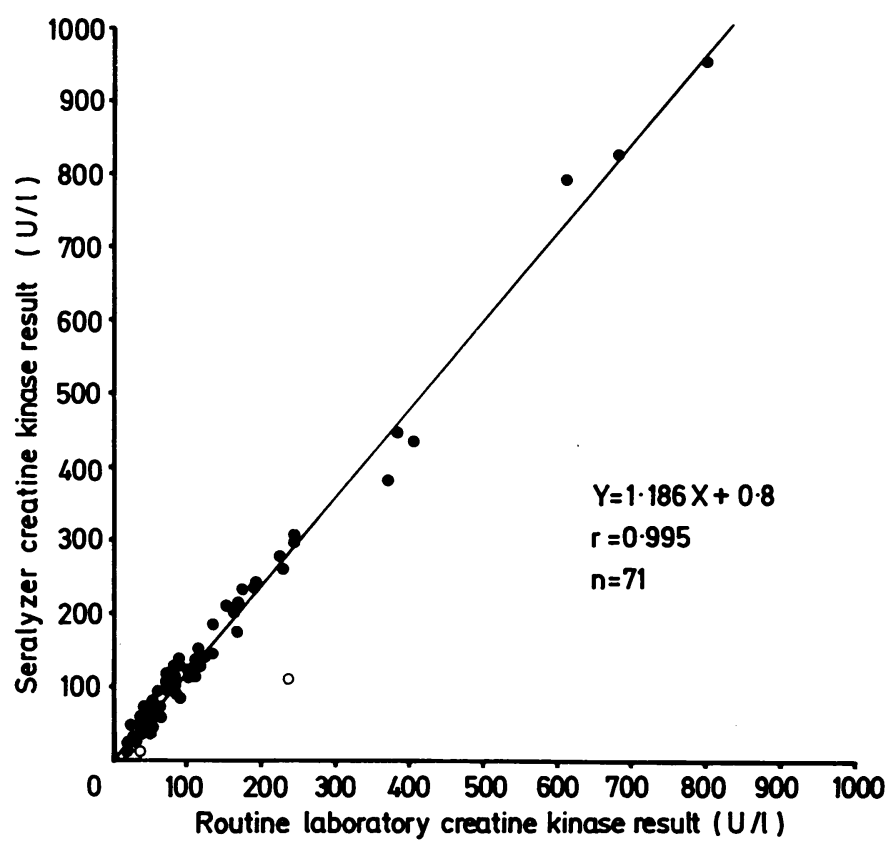

Correlation of Seralyzer creatine kinase results obtained by medical staff with corresponding routine laboratory data. (Two open circles represent measurements performed incorrectly by Seralyzer.)

Twenty nine samples submitted for routine cardiac enzyme profile after Seralyzer analysis were returned to the coronary care unit next day for reanalysis. The mean creatine kinase activity for this group was $254 \mathrm{U} / 1$ (range 81-370 U/l) and the coefficient of variation for the replication $7.9 \%$. Table III shows the improved availability of creatine kinase results using the Seralyzer in the coronary care unit for patients admitted during laboratory hours and outside those hours including weekends. The improved availability of results during a bank holiday weekend is shown separately.

TABLE III-Improvements in availability of creatine kinase results using Seralyzer in coronary care unit

\begin{tabular}{lcc}
\hline & \multicolumn{2}{c}{ Improvement in availability (hours) } \\
\cline { 2 - 3 } Sample collection time & Mean & Range \\
\hline $0900-1700$ & $23 \cdot 2$ & $6 \cdot 5-53 \cdot 0$ \\
$1700-0900$ & $21 \cdot 8$ & $9 \cdot 0-46 \cdot 5$ \\
April bank holiday (1200 Saturday till & $70 \cdot 3$ & $44 \cdot 5-102 \cdot 0$ \\
0900 Tuesday) & & \\
\hline
\end{tabular}

\section{Discussion}

Among the fundamental criteria for decentralised biochemical testing is the need for acceptable levels of precision and accuracy to be achievable by all users of analytical equipment located peripherally. Doubts have been expressed about the standard of performance of non-laboratory workers using decentralised equipment, ${ }^{6}$ ' but this study showed that essentially comparable precision was attained for Seralyzer creatine kinase determinations by doctors on the coronary care unit and laboratory workers alike. The level of precision achieved in this study by medical staff was also comparable with the findings published by other laboratory workers. ${ }^{8} 9$ Indeed, the reproducibility of the determination when performed by medical staff made the single analysis of samples reliable enough for diagnosis. During the clinical evaluation all eight duty doctors used the Seralyzer so that, while all were proficient in its use, none became sufficiently "expert" to bias the overall assessment of the reliability of the data. Although precision for both groups of users was generally poorer than for laboratory creatine kinase analyses-as would be expected from the relatively higher degree of manual work needed for Seralyzer measurements-only the control sample 
data produced by the medical staff differed in statistical significance. We believe that this reflects sample instability ${ }^{10}$ rather than simply operator or instrument performance and emphasises the need for careful planning of quality control measures adopted for equipment in use outside the main laboratory. Patients' plasma creatine kinase activities did not show such lability. Using correlation of results with the routine laboratory method as a practical measure of accuracy, both groups found similar positive Seralyzer bias with patients' plasma samples. This has not been observed before, ${ }^{8}{ }^{9}$ but difference in calibration materials and the laboratory instruments used for comparisons may account for the finding. The Seralyzer proved reliable throughout, requiring little maintenance other than daily provision of control materials and occasional calibration.

Decentralised testing must make a measurable and economic contribution to patient care, as its use cannot be justified on the ground of technological progress alone. The instrument costs $£ 2900$ and creatine kinase test strips cost $44.8 \mathrm{p}$ each (both excluding VAT). In view of the time taken to produce controlled results, however, the logical role of the Seralyzer would not be to replace the routine enzyme service from the laboratory but to supplement that service for selected admissions. The ability of medical staff to identify those patients who were less likely to have their management altered by enzyme analysis on admission points to the probable success of such a selective policy and is consistent with the need to exercise discretion in requesting tests. ${ }^{11}$ The added burden of analysis was thus small and well accepted as the doctors were motivated to produce results of immediate diagnostic utility. The substantial improvement in availability of creatine kinase estimations, particularly at weekends and on a bank holiday when the routine laboratory service was not available, contributed to overall economies, principally in the early discharge of patients from costly intensive care facilities to the general ward or even home.
In conclusion, we have shown that standards of precision and accuracy for Seralyzer creatine kinase analyses similar to those achieved by experienced analysts in the laboratory were attainable by doctors on a coronary care unit. The medical staff were able to produce rapid, reliable results by adhering to a simple analysis protocol after only minimal training in the use of the instrument. Such "real time" cardiac enzyme data aided earlier confirmation of diagnosis and facilitated appropriate patient management. Continuing success in the use of the Seralyzer, however, depends on day to day cooperation with the laboratory to ensure maintenance of performance quality and therefore maximum diagnostic reliability of results.

We are grateful to the Ames Division of Miles laboratories for the loan of the Seralyzer reflectance photometer for this study.

\section{References}

1 Zipp A. Development of dry reagent chemistry for the clinical laboratory. fournal of Automatic Chemistry $1981,3: 71-5$.

作

Weiner K. Pathology measurements closer to the patient? f Clin pathol 1980;33 : $857-63$.

Watson D. Analytical investigations closer to the patient. Br Med F 1980;281:31-5. Marks V. Clinical biochemistry nearer the patient. Br Med f 1983;286:1166-7. Drucker RF, Williams DRR, Price CP. Quality assessment of blood glucose monitors in use outside the hospital laboratory. F Clin Pathol 1983;36:948-53. ans SE, Buckley BM. Biochemists nearer the patient? Br Med $\mathcal{f} 1983 ; 287$

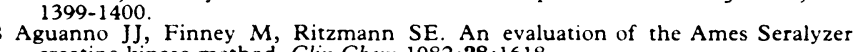
creatine kinase

Stevens JF, Tsang W, Newall RG. Measurement of the enzymes lactate dehydrogenase and creatine kinase using reflectance spectroscopy and reagent strips. genase and creatine kinase using
$\mathcal{F}$ Clin Pathol 1983;36:1371-6.

10 Perry B, Doumas B, Jendrzejczak B. Effect of light and temperature on the stability of creatine kinase in human sera and controls. Clin Chem 1979;25 $625-8$

11 Mitchell JRA, Wilcox RG, Hampton JR. Necessary tests or ritual dances ? Lancet 1982 ;ii:990.

(Accepted 31 fanuary 1985)

Royal Naval Hospital, Haslar, Gosport, Hampshire

T GLEDHILL, CHM, FRCS, research fellow

R J LEICESTER, MB, FRCS, consultant surgeon

B ADDIS, MRCPATH, DCP, consultant pathologist

N LIGHTFOOT, MB, MRCPATH, consultanı microbiologist

RICHARD H HUNT, MB, FRCP, consultant physician

Smith Kline and French Research Ltd, Welwyn, Hertfordshire

J BARNARD, MB, MRCP, senior medical adviser

N VINEY, BSC, chemist

D DARKIN, BSC, senior chemist

Correspondence to: Professor Richard H Hunt, Division of Gastroenterology, McMaster University Medical Centre, Hamilton, Ontario, Canada.

No endoscopic abnormality was seen at one and eight months, but biopsies showed active superficial gastritis, which resolved in one subject and became chronic in two. Schilling tests performed in three subjects at eight months showed diminished retention of vitamin $B_{12}$. During hypochlorhydria a 24 hour intragastric analysis was performed for total and nitrate reducing bacteria, $\mathrm{pH}$, and concentrations of nitrite and total and stable $N$-nitroso compounds. Of the 48 samples of gastric juice examined, 47 had bacterial growth of more than $10^{\circ}$ organisms $/ \mathrm{ml}$ and 46 had growth of nitrate reducing bacteria of more than $10^{5} \mathrm{organisms} / \mathrm{ml}$. Mean intragastric nitrite concentrations were 10 times higher than in a group of eight healthy controls. Both mean total and mean stable $N$-nitroso compound concentrations, however, were not appreciably different from those in controls.

Although community transmission was a possibility, serological screening and electron microscopy of gastric biopsy specimens failed to show an infective cause. Transmission of an unidentified enteric pathogen via a contaminated $\mathrm{pH}$ electrode was therefore suspected. Thus gastric juice should not be returned to the stomach after contact with a contaminated glass electrode as this is a possible cause of atrophic gastritis. 